\title{
Dissymmetric Gemini Surfactants Generated by Disulfide Exchange in Mixed Micelles
}

\author{
Tsuyoshi Asakawa*, Hirotaka Tango, Tadahiro Ozawa and Akio Ohta \\ School of Chemistry, College of Science and Engineering, Kanazawa University (Kanazawa 920-1192, JAPAN)
}

\begin{abstract}
We found the generation of dissymmetric gemini surfactants from symmetric ones in aqueous micelle solutions of gemini surfactants with a spacer containing disulfide linkage. The equilibrium was attained during $5 \mathrm{~h}$ incubation at $25^{\circ} \mathrm{C}$ with $1: 2$ ratio of symmetric to dissymmetric ones when the total concentrations were sufficiently high compared with monomer concentrations. The generation of dissymmetric form is attributed to the disulfide exchange between the spacer chains, which occurs in the mixed micelles of gemini surfactants with different hydrocarbon chains. The pseudo-phase separation model for micellization was successfully used to predict not only the cme of binary and ternary mixtures composed of symmetric and dissymmetric gemini surfactants but also the monomer concentrations after the equilibrium. Reversibility of the disulfide exchange was ascertained by the generation of symmetric gemini surfactants from dissymmetric ones.
\end{abstract}

Key words: dissymmetric gemini surfactant, disulfide linkage, disulfide exchange, mixed micelle, HPLC analysis

\section{INTRODUCTION}

Gemini surfactants usually consist of two hydrophobic chains with same chain lengths ${ }^{1)}$. The symmetrical gemini surfactants have been investigated well owing to the unique properties different from those of conventional single-chain surfactants ${ }^{2)}$. Recently, some properties of dissymmetric gemini surfactants have been investigated, and it has been clarified that the dissymmetry influences on the micellization process ${ }^{3-5}$. The effects on the micellization increased as the degree of dissymmetry increased. With the increase in the degree of dissymmetry, the critical micelle concentration ( $\mathrm{cmc}$ ) decreases linearly, the micelle aggregation number increases slightly, the micelle ionization degree decreases slightly, and so on. Wang et al. suggested that the intermolecular and intramolecular interactions between the hydrophobic alkyl chains exist for the symmetric gemini surfactants, while the intramolecular interaction weakens as the degree of dissymmetry increases ${ }^{4)}$. Thus, the hydrophobic interaction of dissymmetric gemini surfactants must be different from that of symmetric ones.

Disulfide bonds are well known to undergo thiol-disulfide exchange reaction ${ }^{6}$. Regen et al. developed the so-called "nearest-neighbor recognition" method using disulfide linked phospholipids, homodimers $\mathrm{A}-\mathrm{A}$ and $\mathrm{B}-\mathrm{B}^{7,8}$. They indicated that the equilibrium constant $K=[\mathrm{A}-\mathrm{B}]^{2} /[\mathrm{A}-\mathrm{A}][\mathrm{B}-\mathrm{B}]=4$ when $A$ and $B$ mix ideally. The homodimer $(A-A)$ to heterodimer $(\mathrm{A}-\mathrm{B})$ ratio of $1: 2$ is attained due to the disulfide exchange if dimers are randomly distributed and have no thermodynamic preference. In other words, if an equimolar of $(\mathrm{A}-\mathrm{A})$ and $(\mathrm{B}-\mathrm{B})$ were present, the mole ratio of $(\mathrm{A}-\mathrm{A})$ to $(\mathrm{A}-\mathrm{B})$ would be $1: 2$, and the equilibrium constant would be equal to 4 . We should note that the measurements were carried out by promoting thiolate-disulfide interchange reactions with the addition of dithiothreitol. The exchange reaction between disulfide bonds has been scarcely reported because of the stability of the disulfide bond. Recently, Leclaire et al. reported the simultaneous exchange between disulfide bonds in aerated aqueous solutions ${ }^{9}$. HPLC analysis demonstrated that the equilibrium of disulfide exchange was reached in $36 \mathrm{~h}$.

We first attempted to clarify the mixing effects of gemini surfactants in aqueous solution using the surfactants containing a disulfide bond at the center of a spacer chain between the ammonium headgroups. In this work, we found a peculiar behavior in the measurements of the $\mathrm{cmc}$ for the mixed surfactant systems. If the disulfide exchange between gemini surfactants occurs, one type of dissymmetric gemini surfactant can be generated. This may be an origin of the

* Correspondence to: Tsuyoshi Asakawa, School of Chemistry, College of Science and Engineering, Kanazawa University, Kanazawa 9201192, JAPAN

E-mail: asakawa@t.kanazawa-u.ac.jp

Accepted October 7, 2009 (received for review September 15, 2009)

Journal of Oleo Science ISSN 1345-8957 print / ISSN 1347-3352 online

http://www.jstage.jst.go.jp/browse/jos/ 


\section{T. Asakawa, H. Tango, T. Ozawa and A. Ohta}

peculiar behavior of the cmc observed for the mixed gemini surfactants. It should be noted that the disulfide exchange was performed without the addition of dithiothreitol in aerated aqueous solutions at $25^{\circ} \mathrm{C}$.

In the present work, the conditions of HPLC analysis were optimized for the separation and determination of symmetric and dissymmetric geminis. Then, the time course of the concentration change for each surfactant was examined up to the equilibrium. The effects of mixing ratios and concentrations of surfactants were investigated in the mixtures of geminis containing different alkyl chain lengths. The equilibrium constant was estimated by the micellized surfactant concentrations, which were calculated based on the pseudo-phase separation model for micellization ${ }^{10)}$. The reversible conversion between symmetric and dissymmetric gemini surfactants was also checked by the HPLC analysis.

\section{EXPERIMENTAL}

\subsection{Materials}

Bis $[N$-alkyl- $N, N$-dimethyl- $N$-(2-mercaptoethyl $)$ ammonium bromide] disulfide, $\mathrm{C}_{\mathrm{n}} \mathrm{H}_{2 \mathrm{n}+1} \mathrm{~N}^{+}\left(\mathrm{CH}_{3}\right)_{2} \mathrm{CH}_{2} \mathrm{CH}_{2} \mathrm{SS}$ $\mathrm{CH}_{2} \mathrm{CH}_{2} \mathrm{~N}^{+}\left(\mathrm{CH}_{3}\right)_{2} \mathrm{C}_{\mathrm{n}} \mathrm{H}_{2 \mathrm{n}+1} 2 \mathrm{Br}^{-}\left(\mathrm{C}_{\mathrm{n}} \mathrm{SSC}_{\mathrm{n}}\right)$ was prepared by similar procedures to those reported previously as briefly mentioned below ${ }^{11)}$. Bis[2-(N,N-dimethylaminoethyl)] disulfide dihydrochloride (Wako Pure Chemical Industries, Ltd.) was mixed with twice moles of sodium ethoxide in ethanol. After the removal of precipitated $\mathrm{NaCl}$, the solution was stirred with 2.2 times moles of 1-bromoalkane at $40^{\circ} \mathrm{C}$ for 2 days. After the evaporation of ethanol, the products were washed with acetone and were purified by repeated recrystallization from acetone-ethanol mixtures.

\subsection{Measurements}

The gemini surfactants were analyzed by TSKgel ODS-100V (TOSOH Co.) column using methanol / $30 \mathrm{mM}$ sodium 1-octanesulfonate (85:15) mixture as an eluting solution. The elution of surfactant was monitored by CM-8010 (TOSOH Co.) electrical conductivity detector. Aqueous solutions of $\mathrm{C}_{n} \mathrm{SSC}_{\mathrm{n}}$ and $\mathrm{C}_{\mathrm{m}} \mathrm{SSC}_{\mathrm{m}}$ were prepared in volumetric flask separately. The same volumes of $\mathrm{C}_{n} \mathrm{SSC}_{n}$ and $\mathrm{C}_{\mathrm{m}} \mathrm{SSC}_{\mathrm{m}}$ aqueous solution at given concentrations were mixed in test tubes using digital pipette. They were incubated at $25^{\circ} \mathrm{C}$ without stirring. Generated dissymmetric gemini surfactant was isolated by the same HPLC system using $85: 15$ methanol / $0.4 \mathrm{M} \mathrm{NaCl}$ aqueous solution as an eluting solution. The portions of $\mathrm{C}_{\mathrm{m}} \mathrm{SSC}_{\mathrm{n}}$ were collected in test tubes. They were concentrated by evaporation of methanol under reduced pressure. The conductivity measurements of aqueous surfactant solutions were carried out at $25^{\circ} \mathrm{C}$ using a conductivity meter, Model DS-12 (HORIBA).

\section{RESULTS AND DISCUSSION}

3.1 Generation of dissymmetric gemini surfactant from symmetric ones

We have found that the cmc of equimolar $\mathrm{C}_{10} \mathrm{SSC}_{10}-\mathrm{C}_{12} \mathrm{SSC}_{12}$ mixture subjected to incubation was larger than that of fresh-prepared sample. This fact suggested a possibility that a certain chemical reaction took place in the solution during the incubation. In order to check this possibility, HPLC experiments were carried out. Figure 1 shows that a new peak appears in HPLC analysis of $\mathrm{C}_{10} \mathrm{SSC}_{10}-\mathrm{C}_{12} \mathrm{SSC}_{12}$ aqueous solutions during the incubation. The elution peaks of $\mathrm{C}_{10} \mathrm{SSC}_{10}$ and $\mathrm{C}_{12} \mathrm{SSC}_{12}$ were observed at 4.5 and $9.5 \mathrm{~min}$, respectively, while the new peak was detected at $6.1 \mathrm{~min}$. The new peak corresponds to dissymmetric gemini surfactant, $\mathrm{C}_{10} \mathrm{SSC}_{12}$, generated by disulfide exchange between $\mathrm{C}_{10} \mathrm{SSC}_{10}$ and $\mathrm{C}_{12} \mathrm{SSC}_{12}$. The small peak of $\mathrm{C}_{10} \mathrm{SSC}_{12}$ was observed even after 5 min incubation.

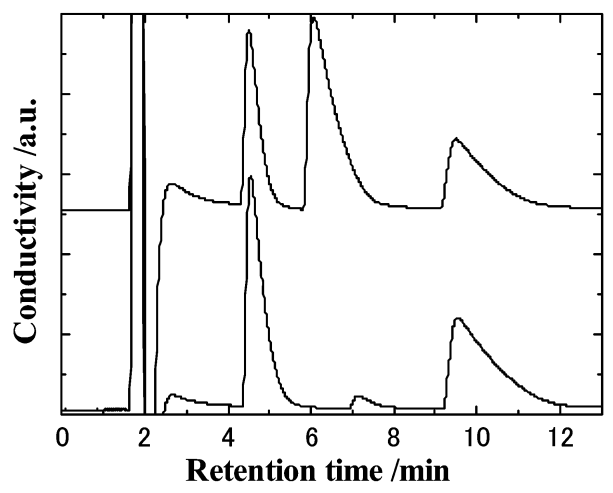

Fig. 1 HPLC Elution Profiles of Gemini Surfactants.

The lower and upper curves correspond to the chromatograms for $5 \mathrm{~min}$ and $5 \mathrm{~h}$ incubations after mixing of $50 \mathrm{mM} \mathrm{C}_{10} \mathrm{SSC}_{10}$ and $50 \mathrm{mM} \mathrm{C}_{12} \mathrm{SSC}_{12}$ aqueous solutions, respectively.

\subsection{Effect of concentration on generation of Dissymmetric gemini surfactant}

Figure 2 shows the time course of the surfactant concentration change observed for $25 \mathrm{mM} \mathrm{C}_{10} \mathrm{SSC}_{10}-25$ $\mathrm{mM} \mathrm{C}_{12} \mathrm{SSC}_{12}$ aqueous solution. The concentrations of both $\mathrm{C}_{10} \mathrm{SSC}_{10}$ and $\mathrm{C}_{12} \mathrm{SSC}_{12}$ decrease with the incubation time, while that of $\mathrm{C}_{10} \mathrm{SSC}_{12}$ increases significantly. The concentration of $\mathrm{C}_{10} \mathrm{SSC}_{10}$ always coincided with that of $\mathrm{C}_{12} \mathrm{SSC}_{12}$ within experimental error. The surfactant concentrations become almost constant after $120 \mathrm{~min}$ incubation. The concentration ratio of $\mathrm{C}_{10} \mathrm{SSC}_{10}$ to $\mathrm{C}_{10} \mathrm{SSC}_{12}$ was almost 1:2 at equilibrium.

$$
\mathrm{C}_{10} \mathrm{SSC}_{10}+\mathrm{C}_{12} \mathrm{SSC}_{12} \rightleftharpoons 2 \mathrm{C}_{10} \mathrm{SSC}_{12}
$$

Similar experiments to $\mathrm{C}_{10} \mathrm{SSC}_{10}-\mathrm{C}_{12} \mathrm{SSC}_{12}$ system were also performed for $\mathrm{C}_{10} \mathrm{SSC}_{10}-\mathrm{C}_{14} \mathrm{SSC}_{14}$ and $\mathrm{C}_{12} \mathrm{SSC}_{12}$ - 


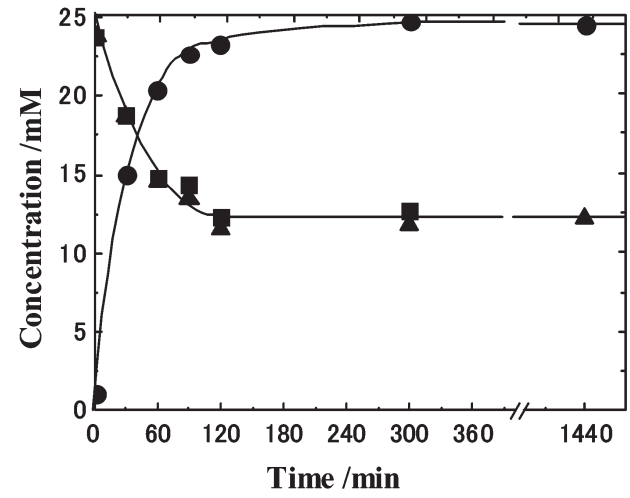

Fig. 2 Time Course of the Concentration Change for 50 $\mathrm{mM}$ Equimolar $\mathrm{C}_{10} \mathrm{SSC}_{10}-\mathrm{C}_{12} \mathrm{SSC}_{12}$ Aqueous Solution Incubated at $25^{\circ} \mathrm{C}$.

The initial concentrations of each surfactant species are $25 \mathrm{mM}$. (ム) $\mathrm{C}_{10} \mathrm{SSC}_{10},(\boldsymbol{\square}) \mathrm{C}_{12} \mathrm{SSC}_{12},(\boldsymbol{O}) \mathrm{C}_{10} \mathrm{SSC}_{12}$

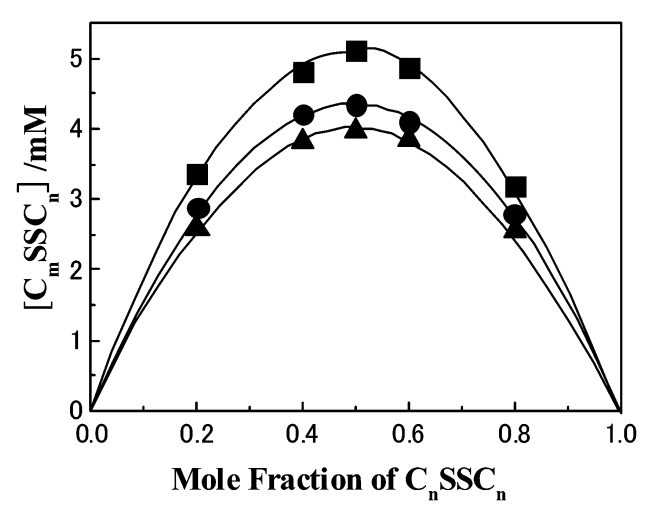

Fig. 3 Concentrations of Generated Dissymmetric Gemini Surfactants at Equilibrium.

Total surfactant concentration is $10 \mathrm{mM}$.

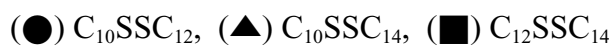

$\mathrm{C}_{14} \mathrm{SSC}_{14}$ systems in the concentration range up to the solubility limit of $\mathrm{C}_{14} \mathrm{SSC}_{14}$. Figure 3 shows the equilibrium concentrations of dissymmetric $\mathrm{C}_{m} \mathrm{SSC}_{n}$ for $\mathrm{C}_{\mathrm{m}} \mathrm{SSC}_{\mathrm{m}}$ $\mathrm{C}_{n} \mathrm{SSC}_{n}$ system as a function of mole fraction of $\mathrm{C}_{n} \mathrm{SSC}_{n}$ at fixed total surfactant concentrations of $10 \mathrm{mM}$. The concentrations of generated dissymmetric $\mathrm{C}_{m} \mathrm{SSC}_{n}$ have a maximum at the equimolar mixtures. The maximum concentration of dissymmetric $\mathrm{C}_{\mathrm{m}} \mathrm{SSC}_{\mathrm{n}}$ is $5.12 \mathrm{mM}$ for $\mathrm{C}_{12} \mathrm{SSC}_{14}$, whereas those for $\mathrm{C}_{10} \mathrm{SSC}_{12}$ and $\mathrm{C}_{12} \mathrm{SSC}_{14}$ are smaller than $5 \mathrm{mM}$. Thus, concentration ratio 1:2 for symmetric $\mathrm{C}_{\mathrm{n}} \mathrm{SSC}_{\mathrm{n}}$ to dissymmetric $\mathrm{C}_{\mathrm{m}} \mathrm{SSC}_{\mathrm{n}}$ is attained only for $\mathrm{C}_{12} \mathrm{SSC}_{12}-\mathrm{C}_{14} \mathrm{SSC}_{14}$ system when total concentration is fixed at $10 \mathrm{mM}$. The generation of dissymmetric $\mathrm{C}_{\mathrm{m}} \mathrm{SSC}_{\mathrm{n}}$ may be influenced by the cmc of surfactant, that is to say, the monomer concentrations in equilibrium with mixed micelles. Thus, the effect of surfactant concentration on the

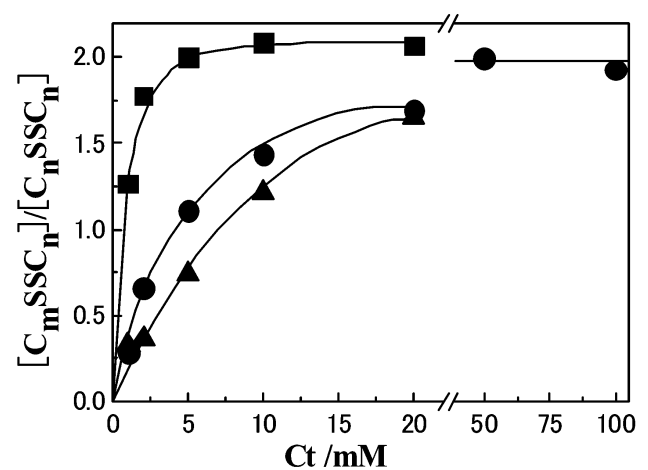

Fig. 4 Dependence of the Generation of Dissymmetric $\mathrm{C}_{\mathrm{m}} \mathrm{SSC}_{\mathrm{n}}$ from Equimolar Mixtures of Symmetric Gemini Surfactants on the Total Surfactant Concentration.

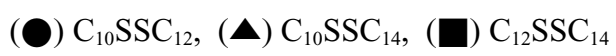

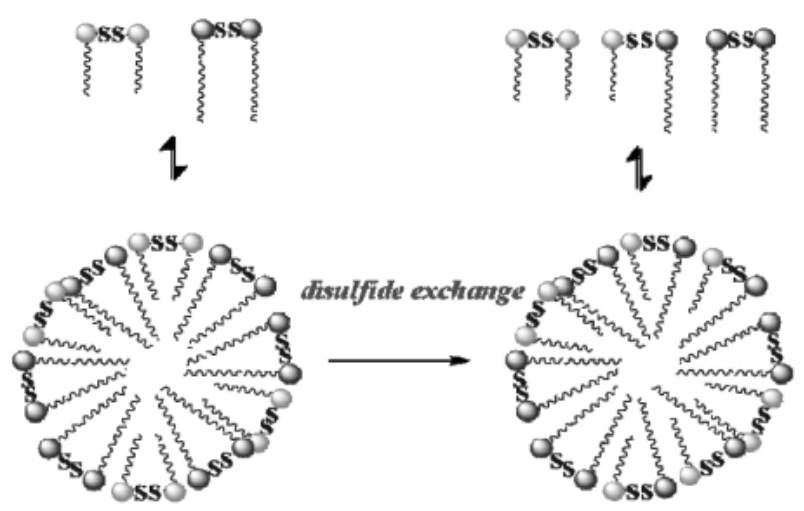

Scheme 1 Disulfide Exchange between Gemini Surfactants in Mixed Micelles.

generation of dissymmetric $\mathrm{C}_{\mathrm{m}} \mathrm{SSC}_{\mathrm{n}}$ was examined.

Figure 4 shows the dependence of the generation of dissymmetric $\mathrm{C}_{\mathrm{m}} \mathrm{SSC}_{\mathrm{n}}$ on total surfactant concentration of equimolar mixture of symmetric gemini surfactants. The total concentrations for $\mathrm{C}_{10} \mathrm{SSC}_{10}-\mathrm{C}_{14} \mathrm{SSC}_{14}$ and $\mathrm{C}_{12} \mathrm{SSC}_{12}$ $\mathrm{C}_{14} \mathrm{SSC}_{14}$ systems were examined up to the solubility limit of $\mathrm{C}_{14} \mathrm{SSC}_{14}$. The concentration of dissymmetric $\mathrm{C}_{\mathrm{m}} \mathrm{SSC}_{\mathrm{n}}$ increases with the increase of the total surfactant concentration. The ratio, $\left[\mathrm{C}_{m} \mathrm{SSC}_{n}\right] /\left[\mathrm{C}_{\mathrm{n}} \mathrm{SSC}_{\mathrm{n}}\right]$, increases up to almost 2 for $\mathrm{C}_{12} \mathrm{SSC}_{12}-\mathrm{C}_{14} \mathrm{SSC}_{14}$ and $\mathrm{C}_{10} \mathrm{SSC}_{10}-\mathrm{C}_{12} \mathrm{SSC}_{12}$ systems at high concentrations, whereas the ratio for $\mathrm{C}_{10} \mathrm{SSC}_{10}-\mathrm{C}_{14} \mathrm{SSC}_{14}$ system is rather low.

Then we tried the disulfide exchange between $\mathrm{C}_{2} \mathrm{SSC}_{2}$ and $\mathrm{C}_{12} \mathrm{SSC}_{12}$ in aqueous solutions. However, $\mathrm{C}_{12} \mathrm{SSC}_{2}$ was not generated during the incubation even for several days. These results suggest that the disulfide exchange can occur in mixed micelles as illustrated in Scheme 1. If this is the case, the concentration of generated dissymmetric $\mathrm{C}_{\mathrm{m}} \mathrm{SSC}_{\mathrm{n}}$ must be dependent on the micellized concentrations of the gemini 


\section{T. Asakawa, H. Tango, T. Ozawa and A. Ohta}

Table 1 Effect of Added Salt toward Generation of Dissymmetric Gemini Surfactant at $25^{\circ} \mathrm{C}$.

\begin{tabular}{cccccc}
\hline $\mathrm{Ct}$ & $\mathrm{NaCI}$ & \multicolumn{3}{c}{ Concentration/mM } & \multirow{2}{*}{ Kapp } \\
\cline { 3 - 5 }$/ \mathrm{mM}$ & $/ \mathrm{M}$ & $\mathrm{C}_{10} \mathrm{SSC}_{10}$ & $\mathrm{C}_{10} \mathrm{SSC}_{12}$ & $\mathrm{C}_{12} \mathrm{SSC}_{12}$ & \\
\hline 10 & 0 & 2.83 & 4.33 & 3.24 & 2.04 \\
10 & 0.4 & 2.20 & 5.22 & 2.58 & 4.80 \\
50 & 0 & 11.6 & 25.5 & 13.8 & 4.06 \\
50 & 0.4 & 10.8 & 24.1 & 12.0 & 4.48 \\
\hline
\end{tabular}

surfactants. Thus, in order to interpret the dependence of $\mathrm{C}_{\mathrm{m}} \mathrm{SSC}_{\mathrm{n}}$ generation on the total concentration, the composition of the mixture, and the species of symmetric gemini surfactants, we should take into account the monomer concentrations, or in other words, the $\mathrm{cmc}$ values for respective surfactant species. The $\mathrm{cmc}$ values of $\mathrm{C}_{10} \mathrm{SSC}_{10}, \mathrm{C}_{12} \mathrm{SSC}_{12}$ and $\mathrm{C}_{14} \mathrm{SSC}_{14}$ have been determined to be $5.85,0.90,0.11 \mathrm{mM}$, respectively, by the conductivity measurements. That is to say, the $\mathrm{cmc}$ of $\mathrm{C}_{10} \mathrm{SSC}_{10}$ is about 50 times larger than that of $\mathrm{C}_{14} \mathrm{SSC}_{14}$. Since the concentration of monomeric $\mathrm{C}_{10} \mathrm{SSC}_{10}$ in $\mathrm{C}_{10} \mathrm{SSC}_{10}-\mathrm{C}_{14} \mathrm{SSC}_{14}$ mixture is much larger than that of monomeric $\mathrm{C}_{14} \mathrm{SSC}_{14}$, the micelle composition is $\mathrm{C}_{14} \mathrm{SSC}_{14}$-rich even for equimolar $\mathrm{C}_{10} \mathrm{SSC}_{10}$ $\mathrm{C}_{14} \mathrm{SSC}_{14}$ system. Therefore, the concentration of generated $\mathrm{C}_{10} \mathrm{SSC}_{14}$ becomes lower than those of other systems.

Figure 4 demonstrates that the concentration of generated dissymmetric $\mathrm{C}_{\mathrm{m}} \mathrm{SSC}_{\mathrm{n}}$ increases and approaches a constant value with the increase of the total surfactant concentration. This is because the micelle composition becomes close to the total composition at high concentration. The similar behavior can be anticipated by the addition of salts, since the coexistence of inorganic salts reduces the cmc. Table 1 shows the effect of $\mathrm{NaCl}$ addition on the concentrations of gemini surfactants at equilibrium. The concentration of generated dissymmetric $\mathrm{C}_{10} \mathrm{SSC}_{12}$ is increased by the addition of $0.4 \mathrm{M} \mathrm{NaCl}$. The concentration ratios of symmetric $\mathrm{C}_{\mathrm{n}} \mathrm{SSC}_{\mathrm{n}}$ to dissymmetric $\mathrm{C}_{\mathrm{m}} \mathrm{SSC}_{\mathrm{n}}$ become to be close to $1: 2$ when the concentration of supporting electrolyte increases. This is because the micelle composition is close to the total composition of the mixed surfactant solution due to the reduced $\mathrm{cmc}$ caused by the addition of $\mathrm{NaCl}$. The apparent equilibrium constant, $K_{\text {app }}$, can be defined as follows using equilibrium concentrations of the three surfactant species in the solution,

$$
K_{\text {app }}=\frac{\left[\mathrm{C}_{10} \mathrm{SSC}_{12}\right]^{2}}{\left[\mathrm{C}_{10} \mathrm{SSC}_{10}\right]\left[\mathrm{C}_{12} \mathrm{SSC}_{12}\right]}
$$

At first glance, the value of $K_{\text {app }}=2.04$ seems to indicate that the generation of dissymmetric gemini surfactant is in disfavor of $\mathrm{C}_{10} \mathrm{SSC}_{10}-\mathrm{C}_{12} \mathrm{SSC}_{12}$ system. However, the value of $K_{a p p}$ becomes about 4 with the increase of total surfactant concentration probably because the monomeric concentrations can be negligible compared with the micellized concentrations.

It is reasonable to assume that the equilibrium of disulfide exchange between gemini surfactants is attained in micelle phase, as mentioned above. Then, the equilibrium constant, $K_{\mathrm{M}}$, should be expressed in terms of equilibrium concentrations of each surfactant species in micelles.

$$
K_{M}=\frac{\left[\mathrm{C}_{10} \mathrm{SSC}_{12}\right]_{\mathrm{M}}{ }^{2}}{\left[\mathrm{C}_{10} \mathrm{SSC}_{10}\right]_{\mathrm{M}}\left[\mathrm{C}_{12} \mathrm{SSC}_{12}\right]_{\mathrm{M}}}
$$

At equilibrium, the aqueous solution contains three components of surfactants. In order to estimate their equilibrium concentrations in micelles from the total concentration, it is necessary to know the monomeric concentrations of each component. We can calculate the monomeric concentrations on the basis of the pseudo-phase separation model for micellization using a regular solution approximation ${ }^{12)}$. According to this model, the total monomeric concentration of ternary system is given by,

$$
C_{m}{ }^{1+K g}=\sum_{i=1}^{3} C_{i}^{1+K g_{i}} x_{i} f_{i}
$$

where $C_{m}$ is cmc of mixed surfactant system, $C_{i}$ is the $\mathrm{cmc}$ of surfactant $i$ in single system, $K g$ is the micelle counterion binding parameter, $x_{i}$ is the mole fraction of surfactant $i$ in the mixed micelle, and $f_{i}$ is the activity coefficient of surfactant $i$ in the micelle. The $K g$ value can be estimated by assuming the additivity of $K g_{i}$, where the subscript $i$ refers to surfactant $i$. The monomeric concentration of surfactant $i$ in the mixture, $\mathrm{C}_{i m}$, can be calculated by the following relation ${ }^{13)}$.

$$
\mathrm{C}_{i m}=\frac{\mathrm{C}_{i}^{1+K g_{i}} x_{i} f_{i}}{\mathrm{C}_{m}{ }^{K g}}
$$

The mole fraction of surfactant $i$ in the mixed micelle is given by the relationship of mass balance.

$$
x_{i}=\frac{\alpha_{\mathrm{i}} C_{t}-C_{i m}}{C_{t}-\sum_{i=1}^{3} C_{i m}}
$$

where $\alpha_{i}$ is the mole fraction of surfactant $i$ in the overall ternary mixture and $C_{t}$ is the total surfactant 
concentration. Thus, we can calculate $C_{i m}$ being in equilibrium with mixed micelles at $C_{t}$ using equations 4 6. However, we cannot determine the $\mathrm{cmc}$ of the dissymmetric gemini surfactant in single system because the symmetric gemini surfactants are soon generated by the disulfide exchange in the micellar aqueous solutions. Therefore, we estimated the $\mathrm{cmc}$ of the dissymmetric gemini surfactant by using the linear relationship between log $\mathrm{cmc}$ and total carbon number $\left(\mathrm{C}_{\mathrm{n}}\right)$ of two hydrophobic chains. The cmc of $\mathrm{C}_{10} \mathrm{SSC}_{12}$ was estimated to be $2.23 \mathrm{mM}$ from the experimental relation of $\log \mathrm{cmc}=2.10-0.216 \mathrm{C}_{\mathrm{n}}$ for $\mathrm{C}_{10} \mathrm{SSC}_{10}, \mathrm{C}_{12} \mathrm{SSC}_{12}$, and $\mathrm{C}_{14} \mathrm{SSC}_{14}$ systems ${ }^{14)}$. For $\mathrm{C}_{10} \mathrm{SSC}_{10}-\mathrm{C}_{10} \mathrm{SSC}_{12}-\mathrm{C}_{12} \mathrm{SSC}_{12}$ ternary system which is shown in the first row of Table 1, the pseudo-phase separation model presuming ideal mixing i.e., $f_{\mathrm{i}}=1$, predicts that the monomer concentrations of $\mathrm{C}_{10} \mathrm{SSC}_{10}$, $\mathrm{C}_{10} \mathrm{SSC}_{12}$ and $\mathrm{C}_{12} \mathrm{SSC}_{12}$ are $1.84,0.83$ and $0.14 \mathrm{mM}$, respectively. Thus, the equilibrium constant for disulfide exchange in the micelle phase can be calculated as $K_{M}=$ $(4.33-0.83)^{2} /(2.83-1.84)(3.24-0.14)=3.99$ by using Eq. 3 and the concentration data listed in Table 1. The $K_{M}$ value is in excellent agreement with the expected $K_{M}=4$.

The $\mathrm{cmc}$ values of the present mixed surfactant systems were determined from conductivity measurements. The $\mathrm{cmc}$ of binary system was obtained by using fresh-prepared aqueous solutions of equimolar symmetric gemini surfactants. On the other hand, the cmc of ternary system was obtained by rapid measurements after the dilution of equilibrated equimolar mixture of symmetric gemini surfactants with total concentration of $100 \mathrm{mM}$ The cmc of equimolar $\mathrm{C}_{10} \mathrm{SSC}_{10}-\mathrm{C}_{12} \mathrm{SSC}_{12}$ was $1.29 \mathrm{mM}$ in accord with calculated $\mathrm{cmc}(1.30 \mathrm{mM})$ presuming ideal mixing. The $\mathrm{cmc}$ of $\mathrm{C}_{10} \mathrm{SSC}_{10}-\mathrm{C}_{10} \mathrm{SSC}_{12}-\mathrm{C}_{12} \mathrm{SSC}_{12}$ (1:2:1) was $1.54 \mathrm{mM}$, which was also in fair agreement with the calculated $\mathrm{cmc}(1.59$ $\mathrm{mM}$ ). The calculation demonstrated that the $\mathrm{cmc}$ value of ternary system was rather larger than that of binary system before disulfide exchange because the concentration of lower cmc component $\left(\mathrm{C}_{12} \mathrm{SSC}_{12}\right)$ decreased, even though the concentration of higher $\mathrm{cmc}$ component $\left(\mathrm{C}_{10} \mathrm{SSC}_{10}\right)$ decreased simultaneously.

\subsection{Generation of symmetric gemini surfactants}

In closing, we should like to confirm the reverse reaction in the chemical equilibrium (1). The dissymmetric gemini surfactant $\left(\mathrm{C}_{10} \mathrm{SSC}_{12}\right)$ was collected by HPLC elution using methanol / $0.4 \mathrm{M} \mathrm{NaCl}$ aqueous solution (85:15) without sodium 1-octanesulfonate because the anionic component can influence the micellization behavior. Figure 5 shows the HPLC analysis of $\mathrm{C}_{10} \mathrm{SSC}_{12}$ aqueous solution. The elution peak of $\mathrm{C}_{10} \mathrm{SSC}_{12}$ was observed, while the small elution peaks of $\mathrm{C}_{10} \mathrm{SSC}_{10}$ and $\mathrm{C}_{12} \mathrm{SSC}_{12}$ were also detected even for the case of 5 min incubation after isolation. After $24 \mathrm{~h}$, the dissymmetric $\mathrm{C}_{10} \mathrm{SSC}_{12}$ decreased, while the symmetric $\mathrm{C}_{10} \mathrm{SSC}_{10}$ and $\mathrm{C}_{12} \mathrm{SSC}_{12}$ increased as expected.

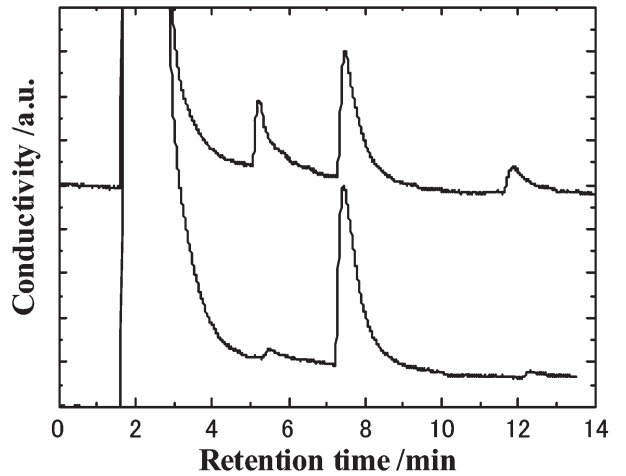

Fig. 5 HPLC Analysis of $0.3 \mathrm{mM} \mathrm{C}_{10} \mathrm{SSC}_{12}$ in $0.4 \mathrm{M} \mathrm{NaCl}$ Aqueous Solutions.

The lower and upper curves correspond to the chromatograms for $5 \mathrm{~min}$ and $24 \mathrm{~h}$ incubations after isolation, respectively.

\section{CONCLUSION}

We found the generation of dissymmetric gemini surfactants from symmetric ones with 1:2 ratio of symmetric to dissymmetric ones when the total concentration was sufficiently high. The concentration of generated dissymmetric $\mathrm{C}_{\mathrm{m}} \mathrm{SSC}_{\mathrm{n}}$ depended on the micellized concentrations of symmetric gemini surfactants, suggesting the occurrence of disulfide exchange in the mixed micelles. The pseudo-phase separation model for micellization predicted the $\mathrm{cmc}$ of binary and ternary mixed surfactant systems composed of symmetric and dissymmetric geminis, which was in accordance with experimentally determined $\mathrm{cmc}$. The model also predicted the monomeric and micellized concentrations, resulting in the equilibrium constant for disulfide exchange in the micelle phase, i.e., $K_{M}=4$. These results indicated the disulfide exchange can occur in the micelle phase as illustrated in Scheme 1.

\section{References}

1. Menger, F.M.; Keiper, J.S. Gemini Surfactants. Angew. Chem. Int. Ed. 39, 1906-1920 (2000).

2. Zana, R.; Benrraou, M.; Rueff, R. Alkanediyl-alpha, omega-bis(dimethylalkylammonium bromide) surfactants. 1. Effect of the spacer chain length on the critical micelle concentration and micelle ionization degree. Langmuir 7, 1072-1075 (1991).

3. Bai, G.; Wang, J.; Wang, Y.; Yan, H.; Tomas, R.K. Thermodynamics of hydrophobic interaction of dissymmetric gemini surfactants in aqueous solutions. J. Phys. Chem. B 106, 6614-6616 (2002).

4. Wang, X.; Wang, J.; Wang, Y.; Ye, J.; Yan, H.; Tomas, R.K. Micellization of a series of dissymmetric gemini sur- 


\section{T. Asakawa, H. Tango, T. Ozawa and A. Ohta}

factants in aqueous solution. J. Phys. Chem. B 107, 11428-11432 (2003).

5. Fan, Y.; Li, Y.; Cao, M.; Wang, J.; Wang, Y.; Tomas, R.K. Micellization of dissymmetric cationic gemini surfactants and their interaction with dimyristoylphosphatidylcholine vesicles. Langmuir 23, 11458-11464 (2007).

6. Lamoureux, G.V.; Whitesides, G.M. Synthesis of dithiols as reducing agents for disulfides in neutral aqueous soluiton and comparison of reduction potentials. $J$. Org. Chem. 58, 633-641 (1993).

7. Davidson, S.M.K.; Regen, S.L. Nearest-neighbor recognition in phospholipid membranes. Chem. Rev. 97, 1269-1279 (1997).

8. Zang, J.; Jing, B.; Tokutake, N.; Regen, S.L. Transbilayer complementarity of phospholipids. A look beyond the fluid mosaic model. J. Am. Chem. Soc. 126, 10856-10857 (2004).

9. Leclaire, J.; Vial, L.; Otto, S.; Sanders, K.M. Expanding diversity in dynamic combinatorial libraries: Simulta- neous exchange of disulfide and thioester linkages. Chem. Commun. 1959-1961 (2005).

10. Abe, M.; Scamehorn, J.F. Mixed surfactant systems. Marcel Dekker Inc. New York (2005).

11. Asakawa, T.; Shimizu, Y.; Ozawa, T.; Ohta, A.; Miyagishi, S. Aqueous solution properties of disulfide linked gemini and cleaved monomeric thiol surfactants. $J$. Oleo Sci. 57, 243-249 (2008).

12. Holland, P.M.; Rubingh, D.N. Nonideal multicomponent mixed micelle model. J. Phys. Chem. 87, 1984-1990 (1983).

13. Davey, T.W.; Warr, G.G.; Asakawa, T. Composition of mixed hydrocarbon and fluorocarbon surfactant adsorbed layers at mica-solution interfaces. Langmuir 19, 5266-5272 (2003).

14. Devinsky, F.; Lacko, I.; Bittererova, F.; Tomeckova, L. Relationship between structure, surface activity, and micelle formation of some new bisquaternary isosteres of 1,5-pentanediammonium dibromides. J. Colloid Interface Sci. 114, 314-322 (1986). 